\title{
Estimating the load response to voltage changes at UK primary substations
}

DOI:

10.1109/ISGTEurope.2013.6695466

Link to publication record in Manchester Research Explorer

\section{Citation for published version (APA):}

Lamberti, F., Dong, C., Calderaro, V., \& Ochoa, L. F. (2013). Estimating the load response to voltage changes at UK primary substations. In 2013 4th IEEE/PES Innovative Smart Grid Technologies Europe, ISGT Europe 2013/IEEE/PES Innovative Smart Grid Technol. Europe, ISGT Europe https://doi.org/10.1109/ISGTEurope.2013.6695466

\section{Published in:}

2013 4th IEEE/PES Innovative Smart Grid Technologies Europe, ISGT Europe 2013|IEEE/PES Innovative Smart Grid Technol. Europe, ISGT Europe

\section{Citing this paper}

Please note that where the full-text provided on Manchester Research Explorer is the Author Accepted Manuscript or Proof version this may differ from the final Published version. If citing, it is advised that you check and use the publisher's definitive version.

\section{General rights}

Copyright and moral rights for the publications made accessible in the Research Explorer are retained by the authors and/or other copyright owners and it is a condition of accessing publications that users recognise and abide by the legal requirements associated with these rights.

\section{Takedown policy}

If you believe that this document breaches copyright please refer to the University of Manchester's Takedown Procedures [http://man.ac.uk/04Y6Bo] or contact uml.scholarlycommunications@manchester.ac.uk providing relevant details, so we can investigate your claim.

\section{OPEN ACCESS}




\section{Estimating the Load Response to Voltage Changes}

\section{at UK Primary Substations}

\author{
Francesco Lamberti \\ Department of Industrial \\ Engineering \\ University of Salerno \\ Fisciano (SA), Italy \\ flamberti@unisa.it
}

\author{
Cuicai Dong \\ School of Electrical and \\ Electronic Engineering \\ The University of Manchester \\ Manchester, UK \\ dongcuicai@gmail.com
}

\author{
Vito Calderaro \\ Department of Industrial \\ Engineering \\ University of Salerno \\ Fisciano (SA), Italy \\ vcalderaro@unisa.it
}

\author{
Luis F. Ochoa \\ School of Electrical and \\ Electronic Engineering \\ The University of Manchester \\ Manchester, UK \\ luis_ochoa@ieee.org
}

\begin{abstract}
The development of Smart Grid technologies and the need to defer investments for expanding and reinforcing distribution networks have attracted new attention to aspects of Conservation Voltage Reduction (CVR). Based on the fact that the demand of certain loads can change with voltage, it is plausible to envisage the active management of voltage regulation devices in order to increase/decrease the demand during certain periods for the benefit of the distribution network (e.g., peak shaving) or the whole system (e.g., fast reserves). The extent of this voltage-driven demand response is however entirely dependent on the instantaneous load composition. In order to quantify the benefits of such a scheme, this work proposes a methodology to estimate the time-varying residential load response to primary substation voltage changes whilst complying with voltage limits at low voltage. This is applied to a small UK distribution network downstream an OLTC-enabled $33 \mathrm{kV} / 6.6 \mathrm{kV}$ substation with 351 residential, 2 commercial and 1 industrial customers (total peak demand of $932 \mathrm{~kW}$ ). The results, only considering part of the residential loads modeled with time-varying ZIP parameters, suggest that even considering voltage constraints- there is considerable load response that can be unlocked from residential loads. However, this is highly dependent on the time of the day.
\end{abstract}

Index Terms-active load management, CVR, demand response, ZIP model, voltage management, voltage regulation, smart grids

\section{INTRODUCTION}

One of the aspects of the transition towards Smart Grids is the ability to manage demand, particularly given the continuous need to defer investments for expanding and reinforcing distribution networks. This is mostly seen from the perspective of the infrastructure needed to integrate participants in demand response schemes (typically involving an economic incentive). However, the advent of advanced capabilities to manage voltages at different distribution levels has attracted new attention to aspects of Conservation Voltage Reduction (CVR).

CVR is based on the simple principle that (certain) loads change with voltage, therefore a reduction in voltage can lead to savings in energy consumption (to customers). This technique has been performed to different extents since the '70s [1]. Initially, the method did not have much adoption mainly because it was difficult to deploy it over a wide area without causing problems to the network and loads (due to voltage drops below statutory limits). Nevertheless, recent studies on voltage optimization and volt-var control, have drawn more attention on CVR [2-4] given that they could, in the future, allow controlling voltages accordingly.

From the perspective of a distribution network operator (DNOs) subject to unbundling rules (such as in Europe), it is therefore plausible to envisage the active management of voltage regulation devices in order to increase/decrease the demand during certain periods for the benefit of the network (e.g., peak shaving, congestion management) or the whole system (e.g., fast reserves). The extent to which this voltagedriven demand response can actually help in managing the network is however entirely dependent on the instantaneous load composition - that might have small changes minute by minute but is significantly different from day to night and from season to season.

On the other hand, the boundaries to which voltage changes can be applied will also depend on how load changes and the corresponding final voltages downstream, particularly for low voltage-connected consumers. Such final voltages should remain within statutory limits and be compliant with standards such as the BS EN50160 [5].

In order to assess the feasibility of the above scheme, this work first estimates the domestic load response to voltage changes whilst complying with voltage limits at low voltage. This is carried out on a UK HV-LV distribution network in the North West of England with 351 residential, 2 commercial and 1 industrial customers, and with a total peak demand of 932 $\mathrm{kW}$. Focus has been given to residential loads of which certain appliances have been modeled aggregating the corresponding ZIP parameters for each customer. This, combined with the corresponding load profiles, allowed the creation of timevarying ZIP models per residential customer. 


\section{Accepted Paper}

Section II contains the analysis of the load profiles and load models, including the time-varying ZIP model. This is implemented on a UK HV-LV distribution network, as described in Section III. Results for 24-hour time-series simulations are the presented highlighting the load response due to the voltage changes on the primary substation. Conclusions are drawn in Section IV.

\section{Methodology}

Primary substations in the UK are those typically transforming $33 \mathrm{kV}$ to $11 \mathrm{kV}$ or $6.6 \mathrm{kV}$. Automatic voltage control systems are used to regulate the voltage target on the secondary using the on load tap changer. These substations are in essence the last elements with controllable voltage capabilities in UK distribution networks. Consequently, they are the most desirable points to assess the effect of voltage changes on (aggregated) load demand.

To model the effects of voltage changes on loads the wellknown ZIP model [6] was used to take into account the corresponding relationship. In particular, the analysis carried out here takes into account the profiles of individual appliances for each house. To reduce the complexity of such a detailed model, time-varying (i.e., changing minute by minute) aggregated ZIP parameters are produced per household. This is explained in the following subsections.

\section{A. Load Profiles}

In order to achieve a time-series simulation the profiles of industrial and commercial customers are obtained through a historic, aggregated half-hourly yearly load profiles (produced by Elexon [7]).

The profiles of the residential customers are produced using a high-resolution (e.g., minute by minute) model developed by CREST (Centre for Renewable Energy Systems Technology) [8] at Loughborough University. In addition, UK National Statistics were adopted to determine the occupancy of households (29\% with $1,35 \%$ with $2,16 \%$ with 3 and $20 \%$ with 4 people) [9]. A typical daily profile of a UK residential customer (4 people) for a weekday in December is shown in Fig. 1.

\section{B. ZIP Model}

The traditional ZIP model is the sum of three timeinvariant terms: constant impedance, constant power and constant current [6]. The active and reactive power consumption in the polynomial formulation is given by (1) and (2). Eq. (3) is a normalized constraint for (1) and (2) that forces the load to consume rated power at rated voltage.

$$
\begin{gathered}
P_{\text {load }}=P_{\text {nom }} *\left(Z_{\text {act }} \frac{V^{2}}{V_{0}^{2}}+I_{\text {act }} \frac{V}{V_{0}}+P_{\text {act }}\right), \\
Q_{\text {load }}=Q_{\text {nom }}\left(Z_{\text {react }} \frac{V^{2}}{V_{0}^{2}}+I_{\text {react }} \frac{V}{V_{0}}+P_{\text {react }}\right), \\
1=Z_{\text {act }}+I_{\text {act }}+P_{\text {act }}, \\
1=Z_{\text {react }}+I_{\text {react }}+P_{\text {react }}
\end{gathered}
$$

where $P_{\text {load }}$ and $Q_{\text {load }}$ are the active and reactive power consumption of the load; $P_{\text {nom }}$ and $Q_{\text {nom }}$ are the active and reactive power consumption at nominal voltage; $V$ is the actual terminal voltage; $V_{0}$ is the nominal terminal voltage $(230 \mathrm{~V}) ; Z_{a c t}, I_{a c t}$, and $P_{a c t}$ are the active power constant impedance, current, and power parameters, respectively; and, $Z_{\text {react }}, I_{\text {react }}$ and $P_{\text {react }}$ are the reactive power constant impedance, current, and power parameters, respectively.

The parameters considered in this work are shown in Table 1. Column \% indicates the percentage of users with a similar residential load according to UK National Statistics [10].

\begin{tabular}{|c|c|c|c|c|c|c|c|c|c|}
\hline \multicolumn{4}{|c|}{ Appliance Data } & \multicolumn{6}{|c|}{ Zip Parameters } \\
\hline \multirow{2}{*}{ Name } & \multirow{2}{*}{$\begin{array}{c}\text { S0 } \\
\text { (VA) }\end{array}$} & \multirow{2}{*}{ pf } & \multirow{2}{*}{$\%$} & \multicolumn{3}{|c|}{ Active Power } & \multicolumn{3}{|c|}{ Reactive Power } \\
\hline & & & & Z\% & $I \%$ & P\% & $Z \%$ & $I \%$ & P\% \\
\hline $\mathrm{Tv}(\mathrm{Crt})$ & 150 & 0.99 & 0.48 & 0.00 & 1.24 & -0.24 & 0.00 & 0.00 & -1.00 \\
\hline Tv(Plasma) & 470 & 0.99 & 0.50 & -0.27 & 0.44 & 0.83 & -1.95 & 2.32 & -1.37 \\
\hline Dishwasher & 1500 & 0.80 & 0.34 & 0.10 & 0.10 & 0.80 & 1.54 & -1.43 & 0.89 \\
\hline Oven & 2500 & 1.00 & 0.62 & 1.00 & 0.00 & 0.00 & 0.00 & 0.00 & 0.00 \\
\hline Kettle & 2000 & 1.00 & 0.98 & 1.00 & 0.00 & 0.00 & 0.00 & 0.00 & 0.00 \\
\hline Wash.Machine & 1065 & 0.61 & 0.93 & 0.06 & 0.31 & 0.63 & -0.56 & 2.20 & -0.64 \\
\hline Fridge & 225 & 0.84 & 0.99 & 1.19 & -0.26 & 0.07 & 0.59 & 0.65 & -0.24 \\
\hline$P C$ & 150 & 1.00 & 0.77 & 0.00 & 0.00 & 1.00 & 0.00 & 0.00 & 0.00 \\
\hline Microwave & 1300 & 1.00 & 0.85 & -2.78 & 6.06 & -2.28 & 0.00 & 0.00 & 0.00 \\
\hline Hob & 2500 & 1.00 & 0.46 & 1.00 & 0.00 & 0.00 & 0.00 & 0.00 & 0.00 \\
\hline Heater & 1500 & 1.00 & 0.50 & 1.00 & 0.00 & 0.00 & 0.00 & 0.00 & 0.00 \\
\hline Light Bulb & 70 & 1.00 & 1.00 & 0.57 & 0.43 & 0.00 & 0.00 & 0.00 & 0.00 \\
\hline
\end{tabular}

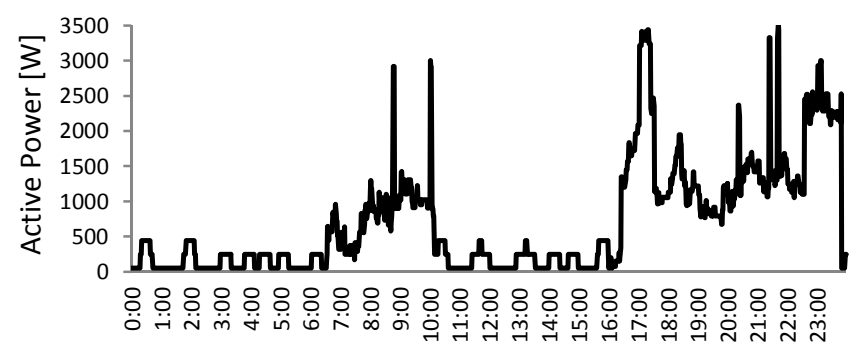

Figure 1. Typical 4-people residential profile (December, weekday).

TABLE 1. ZIP PARAMETERS (230 V) [11],[12]

\section{Time-varying ZIP Model}

In order to reduce the number of loads to be modeled (i.e., each appliance per household), a polynomial formulation was developed to aggregate the ZIP parameters at a given instant for each residential customer connected to the LV network.

Considering that the active and reactive power for a customer is equal to the sum of the active and reactive power of all appliances connected at a given instant, then it is possible to derive a mathematical formulation of the aggregated ZIP parameters.

Equations (5)-(10) extend the polynomial formulation of the traditional ZIP parameters (1)-(4), for multiple appliances. $P_{\text {tot }}$ and $Q_{\text {tot }}$ are the total active and reactive power of the customer taking into account the actual voltage at the connection point. Furthermore, $P_{0}$ and $Q_{0}$ are the amount of active and reactive power of the same customer considering nominal voltage. They are obtained by adding the nominal active and reactive power of each appliance, $P_{n o m_{i}}$ and $Q_{n o m_{i}}$.

In order to achieve the same formulation of (1) and (2) for (5) and (6) the aggregated ZIP parameters can be expressed as in (11) and (12), where the upper extreme of the summation $N_{\text {load }}$ is the number of the appliances modelled through the 


\section{Accepted Paper}

ZIP, and $Z_{a c t}, I_{\text {act }}, P_{\text {act }}, Z_{\text {react }_{i}}, I_{\text {react }_{i}}$ and $P_{\text {react }_{i}}$ are the ZIP parameters of the $i^{\text {th }}$ appliance with $V_{i}$ terminal voltage.

$$
\begin{aligned}
& P_{\text {tot }}=P_{0}\left(Z_{\text {act }} t_{\text {tot }} \frac{V_{i}^{2}}{V_{0}^{2}}+I_{\text {act }} \text { tot } \frac{V_{i}}{V_{0}}+P_{\text {act }}{ }_{\text {tot }}\right), \\
& Q_{\text {tot }}=Q_{0}\left(Z_{\text {react }} \frac{V_{i}^{2}}{V_{0}^{2}}+I_{\text {react }} \frac{V_{i}}{V_{0}}+P_{\text {react }} \text { tot }\right) \text {, } \\
& P_{0}=\sum_{i=1}^{N_{\text {load }}} P_{\text {nom }_{i}} \\
& Q_{0}=\sum_{i=1}^{N_{\text {load }}} Q_{\text {nom }_{i}},
\end{aligned}
$$

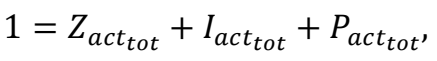

$$
\begin{aligned}
& 1=Z_{\text {react }_{\text {tot }}}+I_{\text {react }_{\text {tot }}}+P_{\text {react }} \text { tot }{ }^{\prime}
\end{aligned}
$$

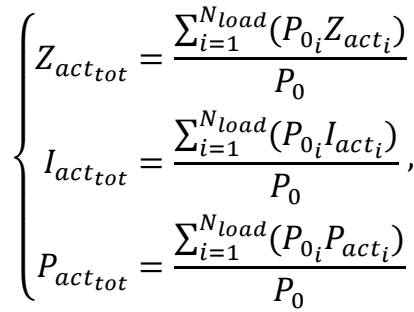

$$
\begin{aligned}
& \left\{\begin{array}{l}
Z_{\text {react }_{\text {tot }}}=\frac{\sum_{i=1}^{N_{\text {load }}}\left(Q_{0_{i}} Z_{\text {react }_{i}}\right)}{Q_{0}} \\
I_{\text {react }_{\text {tot }}}=\frac{\sum_{i=1}^{N_{\text {load }}}\left(Q_{0_{i}} I_{\text {react }_{i}}\right)}{Q_{0}} . \\
P_{\text {react }_{\text {tot }}}=\frac{\sum_{i=1}^{N_{\text {load }}}\left(Q_{0_{i}} P_{\text {react }_{i}}\right)}{Q_{0}}
\end{array}\right.
\end{aligned}
$$

With the above procedure to create time-varying ZIP models it is possible to model a customer with 10 appliances with only 6 parameters instead of 60 . This reduces considerably the management of data.

\section{CASE STUdY}

\section{A. HV-LV Network}

The studied UK HV-LV distribution network is operated by Electricity North West Limited and is located in the North West of England. The single-line diagram is shown in Fig. 2. There are four feeders connected to the busbar of the on-load tap changer-enabled primary substation $(33 \mathrm{kV} / 6.6 \mathrm{kV})$. The topological diagram of the Landgate LV network is presented in Fig. 3. It has six radial feeders and supplies power to 351 residential loads. The corresponding off-load tap changer transformer (blue dot in Fig. 3) is set to have a 5.75\% boost (i.e., $6.6 \mathrm{kV} / 423 \mathrm{~V}$ ).

The minute by minute profiles for the commercial and industrial customers are produced using the historical aggregated Elexon half-hourly profiles [7] combined with recorded maximum values. Fig. 4 shows the estimated profiles

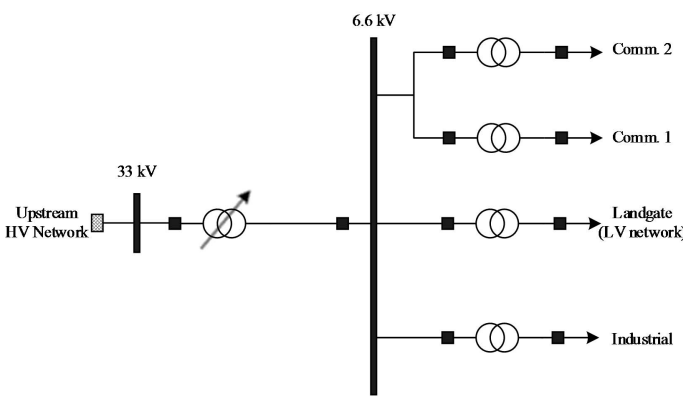

Figure 2. Diagram of the HV network.

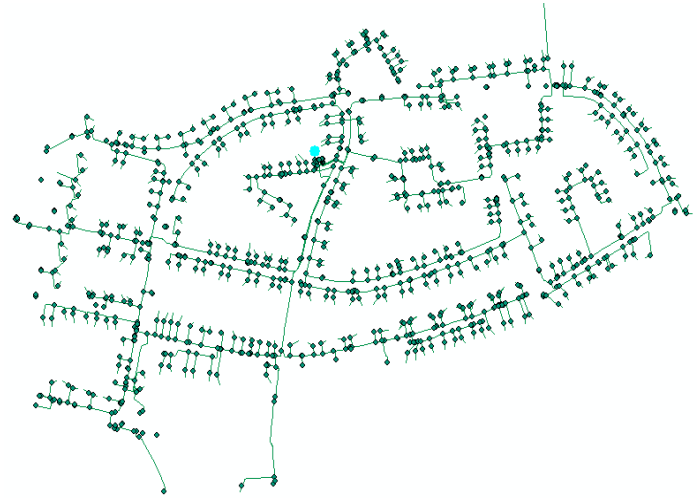

Figure 3. Diagram of Landgate LV network.

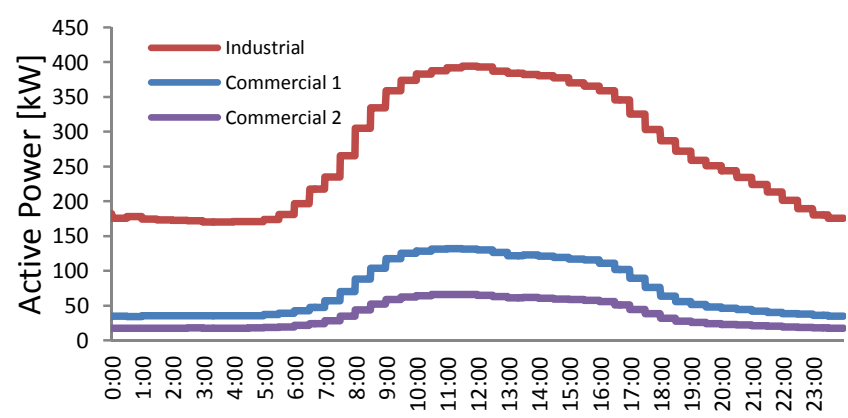

Figure 4. Commercial and Industrial Profiles (19 December 2011).

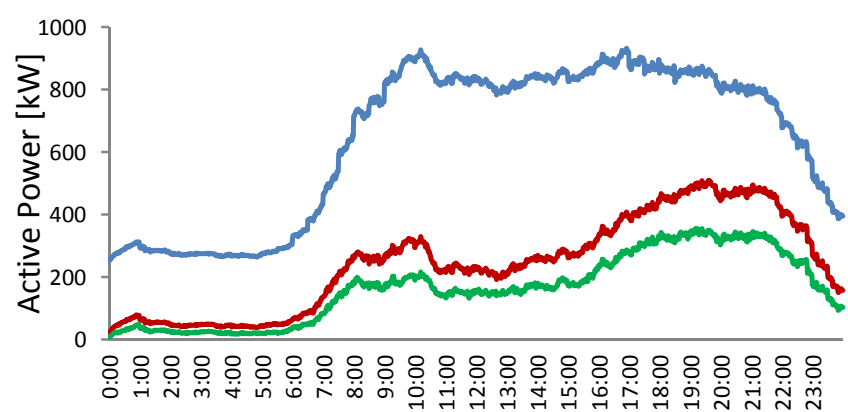

Figure 5. Aggregated active power of the network (blue), aggregated residential demand (red), and aggregated residential demand modeled with ZIP parameters (green)

for 19 December 2011 (with a peak demand of $394 \mathrm{~kW}$ for the industrial load and respectively $132 \mathrm{~kW}$ and $66 \mathrm{~kW}$ for the commercial loads and a power factor of 0.96). On this same day, the peak demand of the residential loads is approximately $500 \mathrm{~kW}$. This particular day will be used in the simulations. OpenDSS [13] and Matlab were used in this study to 


\section{Accepted Paper}

implement the time-varying ZIP parameters and assess the corresponding impacts when changes in voltages are made.

Based on the ZIP parameters available in the literature (see Table 1), it was possible to model approximately $70 \%$ of the residential (active power) peak demand. This represents to around $40 \%$ of the whole peak demand (as shown in Fig. 5) and will be the only part of the load that will respond to changes in voltages.

\section{B. Boundaries for Voltage Changes at the Primary Sub}

The voltage target for the secondary of the primary substation was changed ( 0.01 p.u. steps) in order to assess how the ZIP-modeled load responds and to quantify the final voltages for residential customers. The standard BS EN50160 [5] was adopted to determine whether voltage excursions happened. This standard (adapted for UK LV networks) states that the 10 minute rms phase to neutral voltages should not exceed $10 \%$ of nominal $(230 \mathrm{~V})$. In addition, $95 \%$ of measurements should not be below $6 \%$ of nominal and never below $15 \%$ of nominal. Although the standard considers a week, here it will be used for a day.

The results from the simulations showed that the minimum and maximum feasible voltage targets at the primary substation are 0.97 and 1.02 p.u., respectively. Values outside these limits could result in voltage issues to customers and non-compliance with BS EN50160. The corresponding results for three voltage targets $(1.02,1.00$ and 0.97 p.u.) are presented in Fig. 6. It is important to highlight that although voltage targets of 1.03 and 0.96 p.u. did result in a limited number of excursions (around the $2 \%$ of the daily), a more conservative range was adopted given that the simulations were limited to a day only.

\section{Load Response to Voltage Changes}

In Fig. 7 it is shown the period during the studied day with the largest load responses (in $\mathrm{kW}$ ) to voltage changes. This period corresponds to $6 \mathrm{pm}$ to $7 \mathrm{pm}$ (peak load). In this case, the almost equal power differences between consecutive voltage targets suggest a (close to) linear relationship between load response and voltage change. Indeed, after calculating the coefficient of determination $\left(\mathrm{R}^{2}\right)$ for different instants, around $99 \%$ showed a linear behavior. This, of course, is related to the mix of loads present in the corresponding instant. Consequently, although this relationship is predominant, this cannot be generalized.

The period with the smallest load responses to voltage target changes at the primary substation is presented in Fig. 8. This period corresponds to $4 \mathrm{am}$ to $5 \mathrm{am}$ (minimum load). Also in this case, the results suggest a relationship of load response and voltage changes close to linear.

Considering that typically primary substations in the UK have target voltages above nominal, it can be said that the maximum feasible change in the target voltage for this network is $5 \%$, i.e., from 1.02 to 0.97 p.u. The total load response (both active and complex power) throughout the day

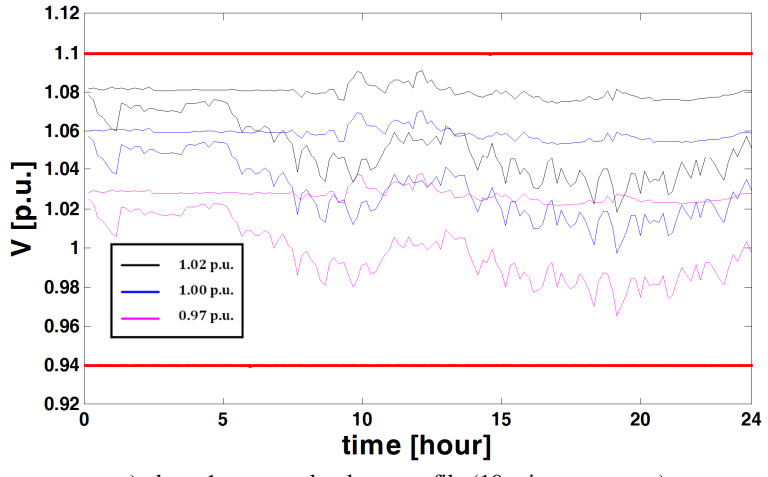

a) phase 1 to neutral voltage profile (10 minute average)

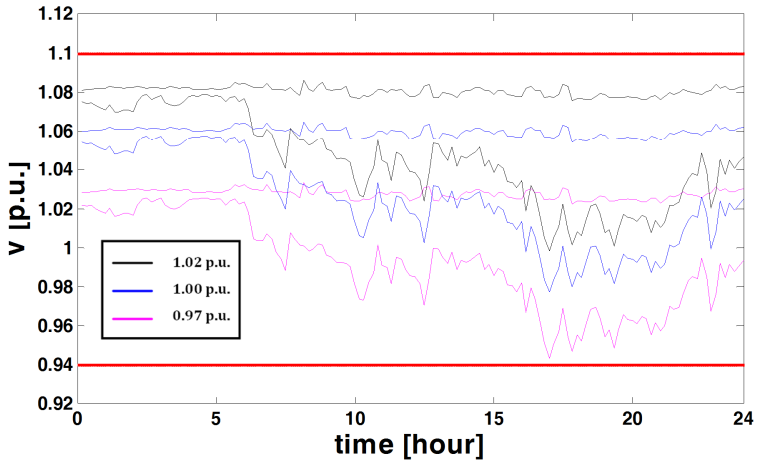

b) phase 2 to neutral voltage profile (10 minute average)

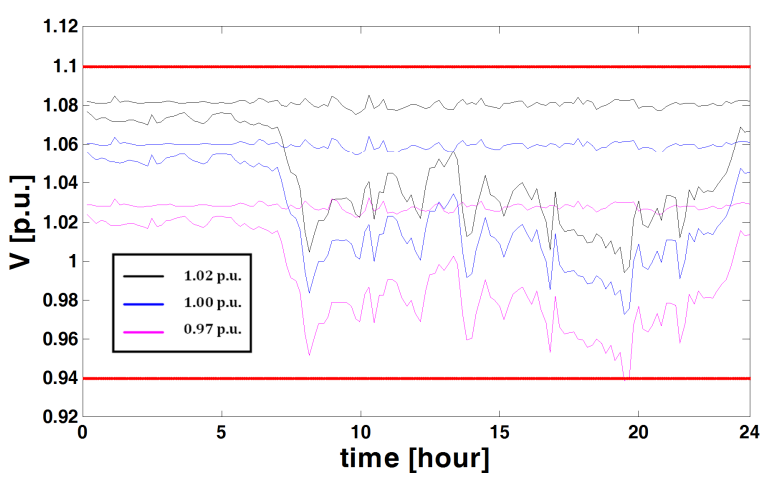

c) phase 3 to neutral voltage profile (10 minute average)

Figure 6. Maximum and minimum voltages found in the LV network for different voltage targets at the primary substation.

or such a change in the voltage target at the primary substation is shown in Fig. 9.

The average (active power) load response throughout the day compared to the total load of the network is $1.75 \%$ with a maximum of $3.24 \%$, as summarized in Table 2 . However, if the average response is compared to the total residential load, this figure goes up to $4.65 \%$. More interesting is the percentage compared to the part of the residential load modeled with the ZIP parameters, with an average of $8.01 \%$. This highlights the importance in adequately modeling most of the load with ZIP parameters to truly quantify the potential effects. During the peak load alone (at 4.56pm), the corresponding figures were 2.22, 4.78 and $7.30 \%$, respectively. The complex power showed a similar trend. 


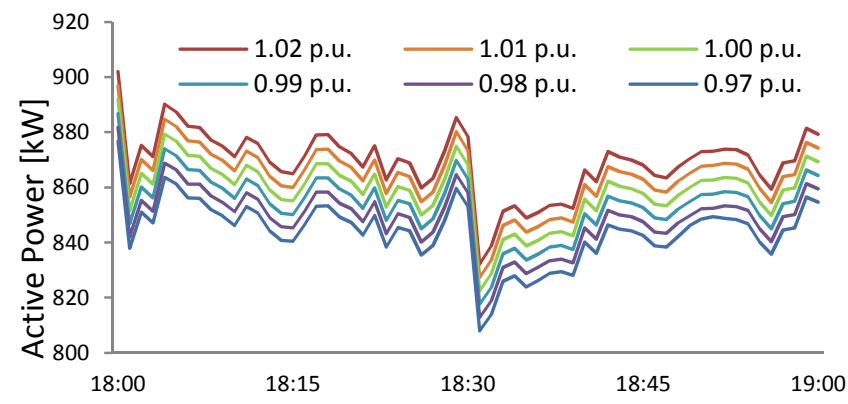

Figure 7. Period with largest load responses to voltage changes.

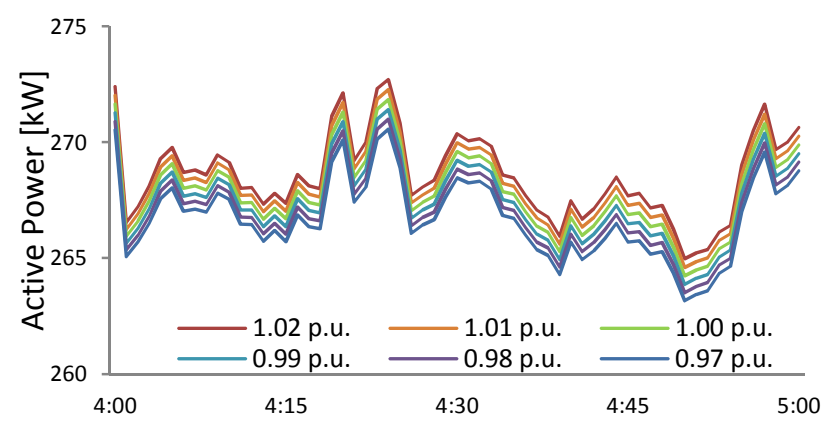

Figure 8. Period with smallest load responses to voltage changes.

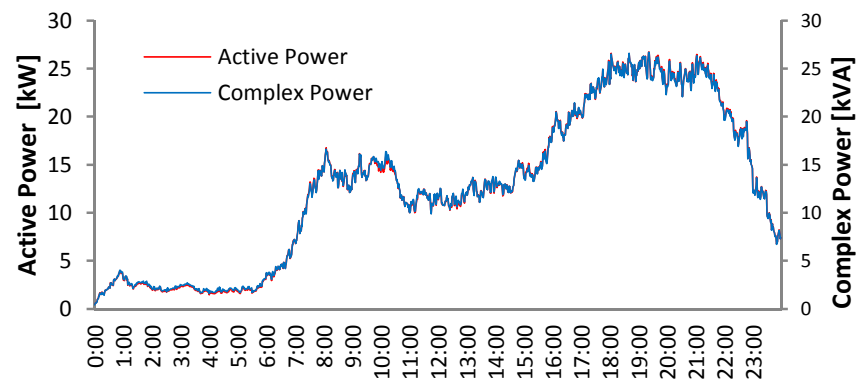

Figure 9. Total load response (active and complex power) for a voltage target change from 1.02 to 0.97 p.u.

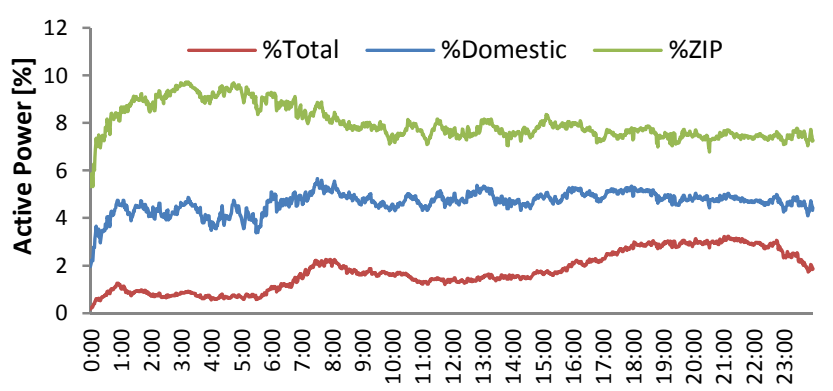

Figure 10. Percentage of active power response during the day compared to different aggregated loads.

TABLE 2. LOAD RESPONSE SUMMARY

\begin{tabular}{|l|c|c|c|}
\hline \multicolumn{1}{|c|}{ Values } & \% Total & \%Residential & \%ZIP \\
\hline Minimum (daily) & 0.17 & 1.96 & 5.31 \\
\hline Maximum (daily) & 3.24 & 5.66 & 9.73 \\
\hline Average (daily) & 1.75 & 4.65 & 8.01 \\
\hline Average (6-7pm) & 2.88 & 5.06 & 7.62 \\
\hline Average (4-5am) & 0.67 & 4.07 & 9.37 \\
\hline
\end{tabular}

\section{CONCLUSIONS}

The quantification of load response to voltage changes in distribution networks is important in the context of
Conservation Voltage Reduction but also due to the potential usages of such a controllable resource if aggregated (e.g., congestion management or provision of reserves).

Here, a methodology was presented by which around $70 \%$ of the peak residential load in a small UK HV-LV network (peak of $932 \mathrm{~kW}$ ) was modelled with time-varying ZIP parameters based on the corresponding appliances used by 'synthetic' households (351, peak of $500 \mathrm{~kW})$. This detailed modelling first allowed determining the feasible ranges of voltage targets (considering BS EN50160) that could be applied to the corresponding OLTC-enabled primary substation $(33 \mathrm{kV} / 6.6 \mathrm{kV})$. Then, it was possible to quantify the load responses to voltage changes.

The results suggest that -even considering voltage constraints- there is considerable load response that can be unlocked from residential loads. However, this is highly dependent on the time of the day. For this particular case study, the active power reductions also presented a linear behavior respect to voltage change. This is likely to be the influence of modeled appliances and their ZIP models.

\section{ACKNOWLEDGMENT}

The authors would like to thank the support of Electricity of North West Limited (ENWL) for the funding and making available the network data. Also to the Centre for Renewable Energy Systems Technology at Loughborough University, $\mathrm{UK}$, for making available the CREST tool.

\section{REFERENCES}

[1] Preiss, R. F.; Warnock, V. J., "Impact of Voltage Reduction on Energy and Demand," Power Apparatus and Systems, IEEE Transactions on, vol.PAS-97, no.5, pp.1665,1671, Sept. 1978

[2] Jauch, E.T., "Volt/var management? An essential "SMART" function," Power Systems Conference and Exposition, 2009. PSCE '09. IEEE/PES , vol., no., pp.1,7, 15-18 March 2009

[3] Ellens, W.; Berry, A.; West, S., "A quantification of the energy savings by Conservation Voltage Reduction," Power System Technology (POWERCON), 2012 IEEE International Conference on, vol., no., pp.1,6, Oct. 30 2012-Nov. 22012

[4] Rahimi, S.; Marinelli, M.; Silvestro, F., "Evaluation of requirements for Volt/Var control and optimization function in distribution management systems," Energy Conference and Exhibition (ENERGYCON), 2012 IEEE International, vol., no., pp.331,336, 9-12 Sept. 2012

[5] BS EN 50160:2010: "Voltage characteristics of electricity supplied by public electricity networks"

[6] "Standard load models for power flow and dynamic performance simulation," Power Systems, IEEE Transactions on, vol.10, no.3, pp.1302,1313, Aug 1995

[7] ELEXON, "Load Profiles and their use in electricity settlement", http://www.elexon.co.uk

[8] Richardson, I.; Thomson, M.; Infield, D.; Clifford, C., "Domestic electricity use: a high-resolution energy demand model"

[9] UK Office for National Statistics, "Families and households, 2001 to 2011," Statistical Bulletin, January 2012

[10] Tsagarakis, G.; Collin, A.J.; Kiprakis, A.E., "Modelling the electrical loads of UK residential energy users," Universities Power Engineering Conference (UPEC), 2012 47th International, vol., no., pp.1,6, 4-7 Sept. 2012

[11] Hajagos, L.M.; Danai, B., "Laboratory measurements and models of modern loads and their effect on voltage stability studies," Power Systems, IEEE Transactions on , vol.13, no.2, pp.584,592, May 1998

[12] Schneider K.P., Tuffner F.K., Fuller J.C., Singh R., "Evaluation of Conservation Voltage Reduction (CVR) on a National Level", July. 2010

[13] http://electricdss.sourceforge.net/ 